\title{
HUBUNGAN KANDUNGAN NITRAT TERHADAP PERTUMBUHAN LAMUN (Enhalus acoroides) DI PESISIR PANTAI NEGERI SULI KECAMATAN SALAHUTU KABUPATEN MALUKU TENGAH
}

\author{
Risaldi Abidin', Jhon F. Rehena ${ }^{2}$ \\ ${ }^{1}$ Alumni Program Studi Pendidikan Biologi \\ ${ }^{2}$ Program Studi Pendidikan Biologi
}

E-mail: johanisrehena@yahoo.com

\begin{abstract}
Background: Seagrass (Enhalus acoroides) is a type of seagrass that has the largest size, leaf strands can reach sizes $>1 \mathrm{~m}$. This type grows in shallow waters to a depth of 4 meters, on the basis of sand, mud sand or mud. The purpose of this study was to determine the relationship of nitrate content to the growth of seagrass (Enhalus acoroides) on the coast of Suli Village Salahutu District, Central Maluku Regency.

Method: The type of research used in this study was descriptive to determine the relationship of nitrate content to growth of seagrass Enhalus acoroides on the coast of Suli State Salahutu District, Central Maluku Regency. The study was conducted on February 1-15, 2018.

Results: This study showed that each transect had different growths of seagrass length, namely on transect 1 , seagrass growth, reaching an average of 1.05 , transect 2 averaging 1.01, while on transect 3 seagrass growth reached 1 average. , 35. Transect 3 has a greater growth rate than transect 1 and transect 2 while transect 2 has a lower growth rate than transect 1 and transect 3 , while the results of the measurement of the average nitrate level on all transects are the same namely at transect 1 of $0.020 \mathrm{mg} / \mathrm{l}$, transect 2 is $0.010 \mathrm{mg} / \mathrm{I}$ and transect 3 is $0.210 \mathrm{mg} / \mathrm{I}$.

Conclusion: Oligtrofic waters have nitrate levels between $0-5 \mathrm{mg} / \mathrm{l}$, mesotrophic waters have nitrate levels between 1-5 mg / I, and eutrophic waters have nitrate levels ranging from 5-50 mg / I.
\end{abstract}

Keywords: Seagrass, nitrate, seagrass growth, Suli Village

\begin{abstract}
Abstrak
Latar Belakang: Lamun (Enhalus acoroides) merupakan jenis lamun yang mempunyai ukuran paling besar, helaian daunnya dapat mencapai ukuran $>1 \mathrm{~m}$. Jenis ini tumbuh di perairan dangkal sampai kedalaman 4 meter, pada dasar pasir, pasir lumpur atau lumpur. Tujuan dari penelitian ini adalah untuk mengetahui hubungan kandungan nitrat terhadap pertumbuhan lamun (Enhalus acoroides) di pesisir pantai Desa Suli Kecamatan Salahutu Kabupaten Maluku Tengah.

Metode: Tipe penelitian yang digunakan dalam penelitian ini adalah deskriptif untuk mengetahui hubungan kandungan nitrat terhadap pertumbuhan lamun Enhalus acoroides di pesisir pantai Negeri Suli Kecamatan Salahutu Kabupaten Maluku Tengah. Penelitian dilaksanakan pada tanggal 01-15 Februari 2018.

Hasil: Penelitian ini menunjukkan setiap transek memiliki pertumbuhan panjang lamun yang berbedabeda yaitu pada transek 1 pertumbuhan lamun rata-rata mencapai 1,05, transek 2 rata-rata mencapai 1,01 , sedangkan pada transek 3 pertumbuhan lamun rata-rata mencapai 1,35. Transek 3 memiliki laju pertumbuhan yang lebih besar dari transek 1 dan transek 2 sedangkan transek 2 memiliki laju pertumbuhan yang lebih rendah dari transek 1 dan transek 3 , sedangkan hasil pengukuran rata-rata kadar nitrat pada semua transek sama yaitu pada transek 1 sebesar 0,020 $\mathrm{mg} / \mathrm{l}$, transek 2 sebesar $0,010 \mathrm{mg} / \mathrm{l}$ dan transek 3 sebesar $0,210 \mathrm{mg} / \mathrm{l}$.

Kesimpulan: Perairan oligtrofik memiliki kadar nitrat antara $0-5 \mathrm{mg} / \mathrm{l}$, perairan mesotrofik memiliki kadar nitrat antara 1-5 mg/l, dan perairan eutrofik memiliki kadar nitrat yang berkisar antara 5-50 mg/l.
\end{abstract}

Kata kunci: Lamun, nitrat, pertumbuhan lamun, Desa Suli. 


\section{PENDAHULUAN}

Indonesia merupakan kawasan kepulauan terbesar di dunia yang terdiri atas sekitar 18.000 pulau besar dan kecil. Indonesia memiliki wilayah perairan laut pesisir dengan keanekaragaman hayati yang cukup tinggi seperti terumbu karang, hutan mangrove, padang lamun, ikan, mamalia dan berbagai jenis moluska. Padang lamun termasuk salah satu ekosistem yang dikenal paling produktif di daerah pesisir (Wibisono M.S. 2005).

Propinsi Maluku merupakan bagian dari negara Indonesia. Luas wilayah provinsi Maluku secara keseluruhan adalah 581.376 $\mathrm{km}^{2}$, yang terdiri dari luas lautan 527.191 $\mathrm{km} 2$ dan luas daratan $54.185 \mathrm{~km}^{2}$. Dengan kata lain sekitar $90 \%$ wilayah provinsi Maluku adalah lautan.

Ekosistern pesisir merupakan ekosistem yang dinamis mempunyai kekayaan habitat yang beragam, di darat maupun di laut serta saling berinteraksi antar habitat. Padang lamun merupakan salah satu ekosistem alami yang sangat luas di lingkungan estuaria dan pesisir serta terrnasuk ekosistem perairan laut dangkal yang khas.

\section{MATERI DAN METODE}

Tipe penelitian yang digunakan dalam penelitian ini adalah penelitian deskriptif untuk mengetahui hubungan kandungan nitrat terhadap pertumbuhan lamun Enhalus acoroides di pesisir pantai Negeri Suli Kecamatan Salahutu Kabupaten Maluku Tengah. Penelitian ini dilakukan di pesisir pantai Negeri Suli Kecamatan Salahutu Kabupaten Maluku Tengah. Penelitian dilaksanakan pada tanggal 01-15 Februari 2018 di Perairan Pantai Negeri Suli Kecamatan Salahutu Kabupaten Maluku Tengah.

Populasi dalam penelitian ini adalah tumbuhan lamun Enhalus acoroides di pesisir pantai Negeri Suli Kecamatan Salahutu Kabupaten Maluku Tengah. Sampel dalam penelitian ini adalah beberapa tegakan daun muda lamun Enhalus acoroides di pesisir pantai Negeri Suli Kecamatan Salahutu Kabupaten Maluku Tengah.

\section{HASIL DAN PEMBAHASAN \\ Parameter Fisika dan Kimia di Perairan Pantai Negeri Suli.}

\section{Parameter fisika (suhu salinitas)}

Suhu merupakan salah satu faktor lingkungan yang dapat mempengaruhi pertumbuhan lamun. Berdasarkan hasil penelitian, suhu di perairan Negeri Suli pada semua transek dengan rata-rata transek 1 dengan kisaran suhu $34^{\circ} \mathrm{C}$, transek 2 dengan kisaran suhu $35^{\circ} \mathrm{C}$ dan pada transek 3 sebesar $37^{\circ} \mathrm{C}$.

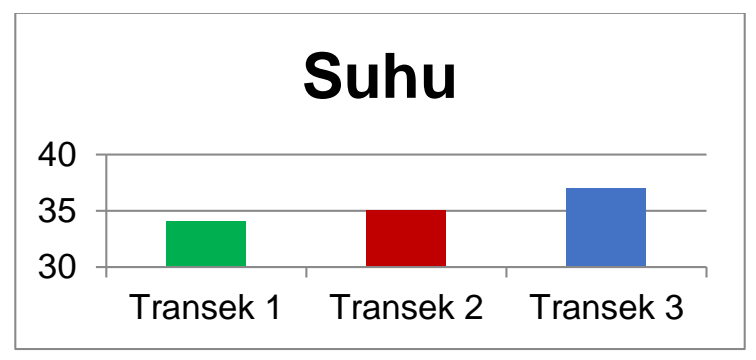

\section{Gambar 1. Grafik Suhu Lokasi Penelitian}

Sedangkan untuk nilai rata-rata pengukuran salinitas di perairan Negeri Suli salinitas pada transek 1 memiliki kisaran salinitas 31\%o, transek 2 memiliki kisaran salinitas $32 \%$, transek 3 memilki kisaran $34 \%$. Tingkat salinitas pada transek 3 lebih tinggi daripada transek 1 dan transek 2.

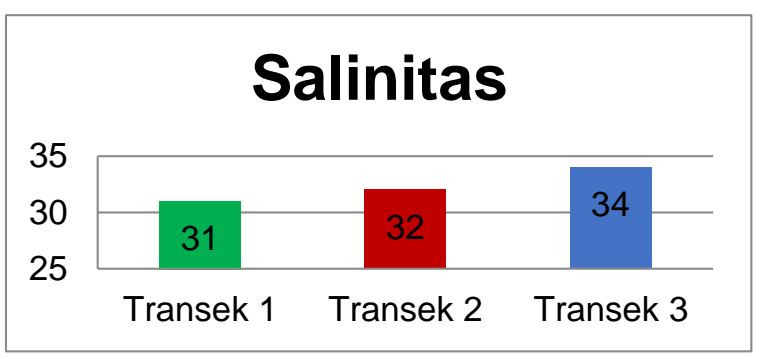

\section{Gambar 2. Grafik Salinitas Lokasi Penelitian}

\section{Parameter kimia (Nitrat, pH dan DO)}

Hasil pengukuran rata-rata kadar nitrat diperairan Negeri suli pada semua transek sama yaitu pada transek 1 sebesar 0,020 $\mathrm{mg} / \mathrm{l}$, transek 2 sebesar $0,010 \mathrm{mg} / \mathrm{l}$ dan transek 3 sebesar $0,210 \mathrm{mg}$. 


\section{Nitrat}

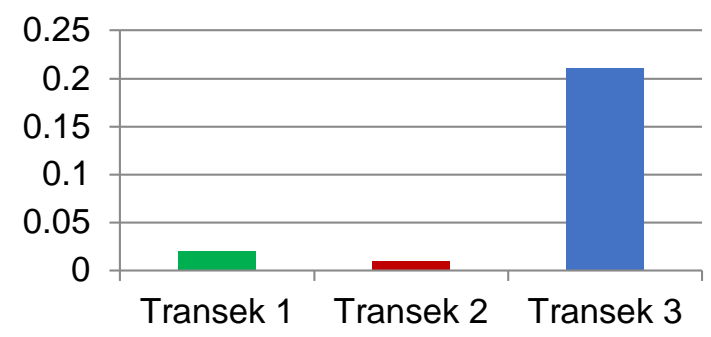

\section{Gambar 3. Grafik Kadar Nitrat Lokasi Penelitian.}

Setelah pengukuran kadar nitrat di lakukan juga pengukuran $\mathrm{pH}$. Hasil penelitian di perairan Negeri Suli nilai $\mathrm{pH}$ yang diperoleh yaitu 8. $\mathrm{pH}$ atau Derajat keasaman mempunyai pengaruh yang besar terhadap tumbuhan dan hewan air. $\mathrm{pH}$ atau Derajat keasaman diperairan Suli dapat dilihat pada Gambar sebagai berikut:

\section{$\mathrm{pH}$}

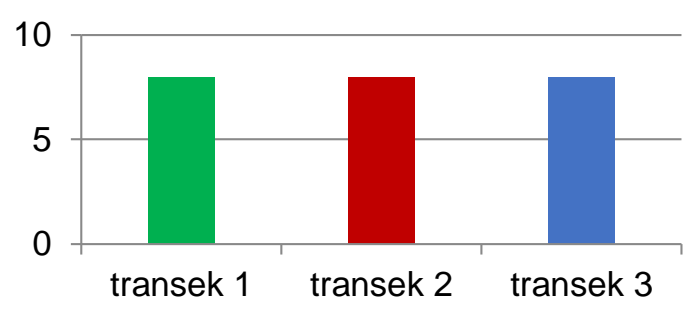

\section{Gambar 4. Grafik pH Lokasi Penelitian}

Setelah pengukuran kadar nitrat dan $\mathrm{pH}$ di lakukan juga pengukuran DO. Hasil penelitian diperairan Negeri suli nilai DO yang diperoleh yaitu pada transek 1 sebesar $8.46 \mathrm{mg} / \mathrm{L}$, transek 2 sebesar 8.24 $\mathrm{mg} / \mathrm{L}$, transek 3 sebesar 7.23. DO diperairan Negeri Suli dapat dilihat pada Gambar sebagai berikut.
DO

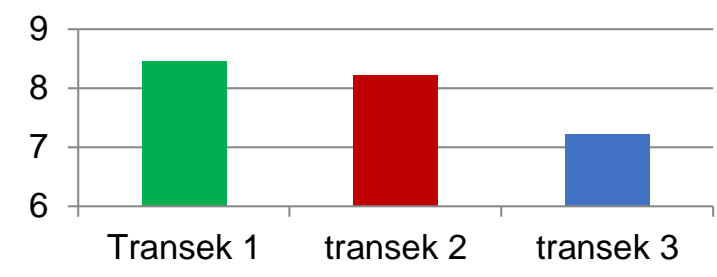

Gambar 5. Grafik DO Lokasi Penelitian

Pertumbuhan Lamun, Pertumbuhan Rata-rata, Pertumbuhan Nisbi dan Hubungan Kandungan Nitrat Terhadap Pertumbuhan Lamun (Enhalus acoroides).

Pertumbuhan daun lamun (Enhalus acoroides).

\section{Pertumbuhan Lamun}

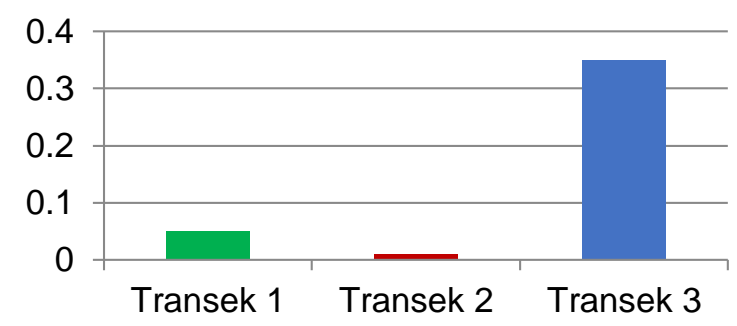

\section{Gambar 6. Grafik Pertumbuhan Panjang Lamun.}

Hasil penelitian yang didapat menunjukan bahwa pada setiap transek memiliki pertumbuhan panjang lamun yang berbeda-beda yaitu pada transek 1 pertumbuhan lamun rata-rata mencapai 1,05, transek 2 rata-rata mencapai 1,01, sedangkan pada transek 3 pertumbuhan lamun rata-rata mencapai 1,35. 


\section{Rata-rata Perhitungan Pertumbuhan Lamun (Enhalus acoroides)}

\section{Pertumbuhan Rata-rata}

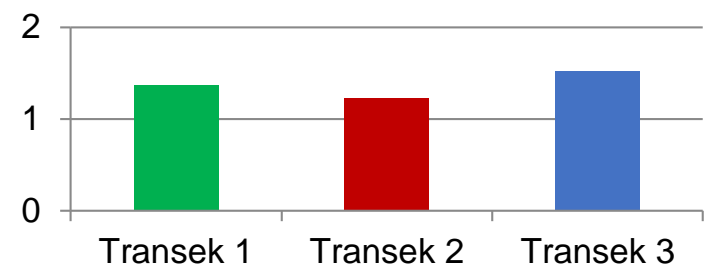

\section{Gambar 7. Grafik Pertumbuhan Rata-rata}

Hasil penelitian menunjukan bahwa pertumbuhan rata-rata lamun Enhalus acoroides diperairan Negeri Suli pada transek 1 sebesar 1,37, transek 2 sebesar 1.22 sedangkan pada transek 3 pertumbuhan rata-rata sebesar 1.52 .

\section{Pertumbuhan nisbi}

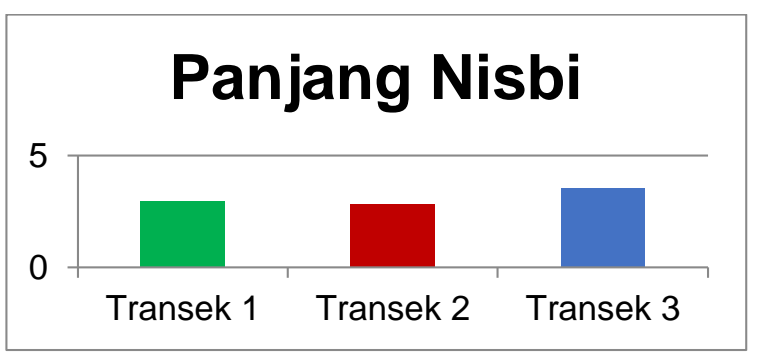

Gambar 8. Grafik Panjang Nisbi

Hasil penelitian menunjukan bahwa pertumbuhan nisbi lamun Enhalus acoroides pada transek 3 lebih besar dibandingkan dengan transek 1 dan transek 2 yaitu sebesar 3.56 sedangkan pada transek 1 dan 2 pertumbuhan nisbi mencapai 2.96 dan 2.86 .

\section{Hubungan kandungan nitrat terhadap pertumbuhan lamun (Enhalus acoroides).}

Berdasarkan hasil penelitian hubungan kandungan nitrat terhadap pertumbuhan lamun Enhalus acoroides yang diukur menggunakan rumus analisis korelasi dengan hasil $r=0.04 \quad(<0.05)$. hal ini menunjukan bahwa terdapat pengaruh kandungan nitrat terhadap pertumbuhan lamun Enhalus acoroides karena nilai yang diperoleh lebih kecil dari 0.05. Dengan demikian, dapat dilihat bahwa kondisi nutrien khususnya nitrat sangat mempengaruhi pertumbuhan lamun Enhalus acoroides dipesisir pantai Negeri Suli Kecamatan Salahutu Kabupaten Maluku Tengah.

\section{KESIMPULAN}

Berdasarkan hasil penelitian yang telah dilakukan dapat disimpulkan bahwa ada hubungan kandungan nitrat terhadap pertumbuhan lamun Enhalus acoroides dipesisir pantai Negeri Suli Kecamatan Salahutu Kabupaten Maluku Tengah. Hal ini dapat dilihat dari analisis korelasi regresi yang dilakukan dimana nilai $r=0.04(<$ 0.05). Berdasarkan dasar pengambilan keputusan pada uji korelasi jika nilai sig < 0.05 maka berkorelasi sebaliknya jika nilai > 0.05 maka tidak berkorelasi. Dengan demikian, dapat dilihat bahwa kondisi nutrien khususnya nitrat sangat berpengaruh nyata terhadap pertumbuhan lamun Enhalus acoroides. Dari hasil ratarata kandungan nitrat dan pertumbuhan lamum sudah terlihat jelas bahwa kandungan nitrat sangat mempengaruhi pertumbuhan lamun. Nitrat yang tinggi membuat pertumbuhan lamun semakin baik. Sebaliknya nitrat yang rendah juga membuat pertumbuhan lamun menjadi kurang baik.

\section{DAFTAR PUSTAKA}

Arikunto, S. 2006. Prosedur Penelitian kuatitatif, Jakarta: Bumi Aksara.

Den Hartog, C. (1977). Structure, function and classification in seagrass communities. In: Seagrass ecosystems: a scientific perspective (C.P. McRoy and C.Helfferich, Eds.). Marcel Dekker, Inc. New York. 89-121.

Effendi, H. 2003. Telaah Kualitas Air Bagi Pengolahan Sumberdaya Hayati Lingkungan Perairan. Kanysius: Yogyakarta.

EFSA. 2008. Nitrate in vegetables. Scientific Opinion of the Panel on Contaminants in the Food Chain. The EFSA Journal 689: 1-79. 
Hendra. 2011. Analisis Penerapan Anggaran Berbasis Kinerja 1, Jurnal Manajemen Kinerja. Tanah Datar.

Kasijan Romimohtarto dan Sri Juwana. Biologi Laut: IImu Pengetahuan Tentang Biota Laut. Cet. Ke-2Jakarta: Djambatan 2005.

KepMen L H, No. 200. 2004. Kriteria Tentang Baku Kerusakan dan Pedoman Penentuan Status Padang Lamun. Keputusan Menteri Negara Lingkungan Hidup. (http://jdih.menlh.go.id/content/docDet ail), diakses 23 Maret 2019.

Soehartono, Irawan. 1995. Metode Penelitian Sosial. Remaja Rosdakarya: Bandung.

Supriadi, Soedharma D, Kaswadji RF. 2006. Beberapa aspek pertumbuhan lamun Enhalus acoroides (Linn. F) Royle di Pulau Barrang Lompo Makasar. Biosfera 23 (1):1-8.

Susetiono. 2004. Fauna Padang Lamun Tanjung Merah Selat Lembeh. Jakarta: Pusat Penelitian Oseanografi, LIPI.

Tuwo, A. 2011. Pengelolaan Ekowisata pesisir dan Laut. Brilian Internasional. Sidoarjo.

Waycott, M., McMahon K, J. Mellors, A. Calladine, and D. Kleine. 2004. A Guide to Tropical Seagrasses of the Indo-West Pacific. James Cook University, Townsville-QueenslandAustralia.

Wibisono M.S. 2005. Pengaturan IImu Kelautan. Jakarta: PT Grasindo.

Ziemen, J.C. 1974. Methods for the study of growth and production of turtle grass. Thalasia testudirum. Konig. Aquacult. 